\title{
Protecting the brain: Do we know the way?
}

\author{
John A. Elefteriades, MD, ${ }^{a}$ and Bulat A. Ziganshin, $\mathrm{MD}^{\mathrm{a}, \mathrm{b}}$
}

See related article on pages S65-73.

Video clip is available online.

Okita and colleagues ${ }^{1}$ are to be congratulated on their article in the Journal for providing a large, thoughtful comparative study, with good clinical results, of 2 different techniques of cerebral protection for total aortic arch replacement. The sheer volume and proportion of total aortic arch replacement cases is astounding. In editorial communications, Okita and colleagues ${ }^{1}$ pointed to the advanced age, liberal use of computed tomographic scanning, and governmental coverage of all surgical costs in Japan as potential factors for the frequency of aortic arch surgery.

Okita and colleagues ${ }^{1}$ found essentially no difference in outcomes between antegrade cerebral perfusion (ACP) and hypothermic circulatory arrest with or without retrograde cerebral perfusion (RCP). The only minor advantages associated with ACP in this study were a shorter intubation time and a shorter intensive care unit stay-not a terribly cogent finding.

The intubation times, however, are very long for both the ACP and hypothermic circulatory arrest with or without RCP groups (83 and 121 hours, respectively). One suspects that this may be due to cerebral edema from excess perfusion of the brain. With straight deep hypothermic circulatory arrest (DHCA), the patients are usually extubated and conversant the afternoon of operation, with "dry," nonedematous brains.

There are some significant deficiencies built in to this study by virtue of its being based on an administrative database. Items of information that would be thought essential for a circulatory arrest study are lacking. Specifically,

From the Aortic Institute at Yale-New Haven Hospital, ${ }^{a}$ Yale University School of Medicine, New Haven, Conn; and Department of Surgical Diseases \#2, ${ }^{\text {b }}$ Kazan State Medical University, Kazan, Russia.

Disclosures: Authors have nothing to disclose with regard to commercial support.

Received for publication Sept 10, 2014; accepted for publication Sept 10, 2014; available ahead of print Oct 5, 2014.

Address for reprints: John A. Elefteriades, MD, Aortic Institute at Yale-New Haven Hospital, 789 Howard Ave, CB-317, New Haven, CT 06519 (E-mail: john. elefteriades@yale.edu).

J Thorac Cardiovasc Surg 2015;149:S74-5

0022-5223/\$36.00

Copyright (c) 2015 by The American Association for Thoracic Surgery

http://dx.doi.org/10.1016/j.jtcvs.2014.09.020 the duration of circulatory arrest is not known, nor is the use or duration of RCP in the hypothermic circulatory arrest with or without RCP group. This detracts considerably from the impact and clinical utility of this study. What do we do with this information without knowing the duration of arrest?

It is hard to envision how this study will change everyday practice. Most likely, this study will allow proponents of each approach to consider themselves justified in continuing their technique of choice.

Perfusion of the brain during aortic surgery is inherently a very attractive concept. ACP has been facilitated dramatically by the advent of right axillary perfusion for cardiopulmonary bypass in aortic arch surgery. The beauty is that the right carotid and right vertebral arteries are perfused automatically, without extra cannulas. The devil, however, is in the details. Multiple unresolved questions persist with regard to ACP. How many vessels do we perfuse? Does perfusion of just one side of the brain (the right) suffice, or do we need to cannulate and perfuse the left carotid as well? How about the left subclavian artery? Do we need to perfuse that as well to provide blood supply to the left vertebral artery? Is our brain vulnerable to the well-known (and potentially catastrophic) vagaries of the circle of Willis? How fast should the flow be? There is growing evidence that the $800 \mathrm{~mL} / \mathrm{min}$ commonly used (or $10 \mathrm{~mL} / \mathrm{kg}$ body weight) is excessive and may contribute to somnolence and protracted (3 months) focal cerebral edema and metabolic imbalance. ${ }^{2}$

We hasten to point out that there was no straight DHCA group in this study (although the use of RCP was optional in the hypothermic circulatory arrest with or without RCP group). At a minimum, straight DHCA offers an elegant simplicity. The surgeon can concentrate on reconstructing the aortic arch, without brain perfusion becoming the operation. Also, straight DHCA is quick-which may be of value in ruptured ascending dissection cases.

An important point to remember is that most strokes in aortic surgery are embolic in origin, and thus not directly attributable to the method of brain preservation. ${ }^{3,4}$

We have accumulated a large series of patients operated with straight DHCA (with no ACP or RCP). ${ }^{3,4}$ We have reviewed the available literature and compared published results among the 3 available techniques: straight DHCA, ACP, and RCP. ${ }^{5}$ Suffice it to say that published series with ACP or RCP do not better the $2.4 \%$ mortality and $1.6 \%$ stroke rates that we were able to document with straight DHCA at our center. ${ }^{4}$ Early in our experience, we confirmed the safety of straight DHCA for 40 minutes; recently, we were able to extend the documented safe 
duration to 50 minutes, long enough to accommodate even complex total arch cases. ${ }^{3,4}$

In the Yale series, we have scrutinized intensely and quantitatively the adequacy of neuroprotection. We recently focused intently on a "high cognitive group" of patients undergoing DHCA who need the highest levels of cognition for their jobs (doctors, lawyers, administrators, professors, PhDs, deans, musicians, artists, etc). ${ }^{6}$ We applied a postoperative cognitive function assessment that compared preoperative and postoperative home and work functional level according to self-observation and the observations of spouses and supervisory informants. There was no difference between preoperative and postoperative levels, and no difference between cases done with DHCA and simpler cases that did not require any cessation of distal perfusion of the brain and body (cases that could be done "with the clamp on"). Cognitive functional level was fully maintained. Most recently, we administered both preoperative and postoperative intensive direct neurocognitive testing, again finding good preservation and no differences from simpler operations. ${ }^{7}$

We therefore have confidence in DHCA. We especially recommend straight DHCA for hemiarch cases and for acute ascending aortic dissection cases. We also recommend straight DHCA for experienced centers, where complex arch operations can be completed reliably in 40 to 50 minutes of arrest time.

Sometimes an image is indeed worth a thousand words. The 78 year-old woman in Video 1 underwent total arch replacement under DHCA. This clip was recorded at the 7 AM rounds the morning after her operation. She was able to spell the surname of the senior author of this editorial (J.A.E.) perfectly-not only forward, but backward as well! Clearly, her cognition was intact. A recent poll of aortic surgical experts found that $48 \%$ still use straight DHCA in some or all of their arch cases. ${ }^{8}$

Debate is likely to continue for many years regarding the optimal method of cerebral preservation. We as surgeons are highly influenced by and partial to methods that we learned in training and by specific early positive or negative practice experiences. The article by Okita and colleagues, ${ }^{1}$ as well as the existing literature, can be used to justify and support all three methods of protection: straight DHCA, $\mathrm{ACP}$, and $\mathrm{RCP}$ - and all three techniques have knowledgeable, experienced, expert proponents.

\section{References}

1. Okita Y, Miyata H, Motomura N, Takamoto S. A study of brain protection during total arch replacement comparing antegrade cerebral perfusion versus hypothermic circulatory arrest, with or without retrograde cerebral perfusion: Analysis based on the Japan Adult Cardiovascular Surgery Database. J Thorac Cardiovasc Surg. 2015;149:S65-73.

2. Pacini D, Di Marco L, Leone A, Tonon C, Pettinato C, Fonti C, et al Cerebral functions and metabolism after antegrade selective cerebral perfusion in aortic arch surgery. Eur J Cardiothorac Surg. 2010;37:1322-31.

3. Gega A, Rizzo JA, Johnson MH, Tranquilli M, Farkas EA, Elefteriades JA Straight deep hypothermic arrest: experience in 394 patients supports its effectiveness as a sole means of brain preservation. Ann Thorac Surg. 2007;84: 759-66; discussion 766-7.

4. Ziganshin BA, Rajbanshi BG, Tranquilli M, Fang H, Rizzo JA, Elefteriades JA Straight deep hypothermic circulatory arrest for cerebral protection during aortic arch surgery: safe and effective. J Thorac Cardiovasc Surg. 2014;148: 888-900.

5. Ziganshin B, Elefteriades JA. Does straight deep hypothermic arrest suffice for brain preservation in aortic surgery? Semin Thorac Cardiovasc Surg. 2010;22: 291-301.

6. Percy A, Widman S, Rizzo JA, Tranquilli M, Elefteriades JA. Deep hypothermic circulatory arrest in patients with high cognitive needs: full preservation of cognitive abilities. Ann Thorac Surg. 2009;87:117-23.

7. Chau KH, Friedman T, Tranquilli M, Elefteriades JA. Deep hypothermic circulatory arrest effectively preserves neurocognitive function. Ann Thorac Surg. 2013;96:1553-9.

8. Ziganshin BA. Which method of cerebral protection do you prefer to use for aortic arch surgery? AORTA. 2013;1:69-70. 